\title{
A demonstração do resultado econômico e sistemas de custeamento como instrumentos de evidenciação do cumprimento do princípio constitucional da eficiência, produção de governança e accountability no setor público: uma aplicação na Procuradoria- Geral do Município de São Paulo*
}

\author{
Valmor Slomski** \\ Guilherme Bueno de Camargo*** \\ Antonio Carlos Cintra do Amaral Filho**** \\ Vilma Geni Slomski*****
}

SumÁrio: 1. Introdução; 2. Fundamentação teórica; 3. Metodologia; 4. Resultados e discussões; 5 . Conclusões.

Summary: 1. Introduction; 2. Theoretical framework; 3. Methodology; 4. Results and discussions; 5 . Conclusions.

Palavras-chave: resultado econômico; sistemas de custeamento; eficiência; governança e accountability.

\footnotetext{
* Artigo recebido em fev. e aceito em maio 2010.

** Doutor em ciências contábeis e professor do Departamento de Contabilidade e Atuária da Faculdade de Economia, Administração e Contabilidade da Universidade de São Paulo. Endereço: Rua Camândulas, 112, ap. 183 - Vila Leopoldina - CEP 05303-030, São Paulo, SP, Brasil. E-mail: valmor@usp.br.

**** Doutor em direito pela Faculdade de Direito da Universidade de São Paulo e procurador do município de São Paulo. Endereço: Rua Araúna, 70 - Planalto Paulista - CEP 04068-090, São Paulo, SP, Brasil. E-mail: gbcamargo@uol.com.br.

***** Mestrando no Programa de Controladoria e Contabilidade FEA/USP e procurador do município de São Paulo. Endereço: Rua Aroaba, 482, ap. 51, bloco B - Vila Leopoldina - CEP 05315-021, São Paulo, SP, Brasil. E-mail: antoniocaf@prefeitura.sp.gov.br.

$* * * * *$ Doutora em educação pela Faculdade de Educação da Universidade de São Paulo e Pósdoutorada em Controladoria e Contabilidade pela FEA/USP e professora no Programa de Pós-graduação da Fundação Álvares Penteado (Fecap). Endereço: Rua Camândulas, 112, ap. 183 — Vila Leopoldina — CEP 05303-030, São Paulo, SP, Brasil. E-mail: vilma.geni@fecap.br.
} 
KEY WORDS: economic result; costing systems; efficiency; governance and accountability.

Este artigo discorre sobre a demonstração do resultado econômico e sistemas de custeamento como instrumentos de evidenciação do cumprimento do princípio constitucional da eficiência, produção de governança e accountability no setor público para a minimização da assimetria informacional entre o Estado e a sociedade. O referencial teórico tem por base os ensinamentos do seminal paper de Ronald Coase (1937), A natureza da firma, transpostos para a administração pública. A pesquisa é descritivo-quantitativa, e os dados, referentes ao exercício financeiro de 2006, foram coletados por meio de análise documental na Procuradoria-Geral do Município de São Paulo (PGMSP). A pesquisa empírica sugere que a demonstração do resultado econômico (R\$ 184.836.115,11) possibilita a evidenciação do cumprimento do princípio constitucional da eficiência, ao comparar a receita econômica produzida (R\$302.894.295,11) aos custos e despesas incorridos na sua prestação ( $R \$ 118.058 .180,00$ ), e cria novo paradigma relacionado aos aspectos de governança e accountability na gestão pública, capaz de produzir informação à sociedade e ao administrador público para a tomada de decisões gerenciais.

The income statement and costing systems as instruments to prove compliance with the constitutional principle of efficiency, governance production and accountability in the public sector: a case at the Public Prosecutors Office in São Paulo

This article discusses the income statement and costing systems as instruments to prove compliance with the constitutional principle of efficiency, governance production and accountability in the public sector so as to minimize the information asymmetry between state and society. The theoretical framework is based on the teachings of the seminal paper by Ronald Coase (1937), "The nature of the firm," adapted to the civil service. The research is descriptive-quantitative, and the data, referring to 2006, was collected through document analysis at the Public Prosecutors Office (PGMSP) in São Paulo. The results of the empirical research suggest that the income statement can reveal compliance with the constitutional principle of efficiency, since it compares the economic revenue ( $\mathrm{R} \$ 302,894,295.11)$ to the costs and expenses incurred (R\$ 118,058,180.00), indicating an economic outcome (R\$ 184,836,115.11). It also creates new paradigms related to governance and accountability in public administration, capable of producing information to society and support for the decision-making process of public administrators.

\section{Introdução}

O Estado e a sociedade travam luta milenar vis-à-vis volume de impostos pagos e o retorno de benefícios. Entende-se que esse tema foi tratado de maneira 
não assertiva pelos responsáveis pela produção de informações que procuram contribuir para a minimização da assimetria informacional entre o Estado e a sociedade, informar superávit ou déficit orçamentário, financeiro ou patrimonial, certamente não tem contribuído para amainar essa desavença.

O volume de recursos disponibilizados pela sociedade para o Estado, via tributação, justifica plenamente o estudo de formas de evidenciação que contribuam para a melhoria da informação produzida pela administração pública no que se refere à prestação de serviços e consumo de recursos. Ao se discutir o tema custos no setor público gera-se a obrigação de se pensar no princípio constitucional da eficiência e em métodos e formas de evidenciá-la.

Desse modo, este artigo discorre sobre a demonstração do resultado econômico e sistemas de custeamento como instrumentos de evidenciação do cumprimento do princípio constitucional da eficiência, produção de governança e accountability no setor público para a minimização da assimetria informacional entre o Estado e a sociedade.

Para o desenvolvimento deste artigo tomou-se a Procuradoria-Geral do Município de São Paulo (PGMSP), cabendo ressaltar que a advocacia pública é atividade típica de Estado, sendo inviável sua substituição integral pela iniciativa privada. Contudo, os dados aqui apresentados servirão para reflexão e discussões futuras quanto à sua aplicabilidade em outras áreas da administração pública. Assim, os valores propostos neste artigo, com vistas a encontrar o custo de oportunidade para os serviços prestados pela PGMSP, objetivam estabelecer um parâmetro de comparação com a advocacia privada para os serviços prestados pelo órgão.

Espera-se que este artigo contribua com a gestão da PGMSP ao aferir o valor econômico que a advocacia pública do município de São Paulo está agregando à sociedade e sirva para que outras entidades apurem seus custos e mensurem o resultado econômico. Pretende-se, também, apresentar um critério de mensuração de eficiência que permita ao gestor público maior transparência em relação às atividades fundamentais do órgão, em que seja possível apontar eventuais ajustes necessários à melhoria dos serviços prestados.

\section{Fundamentação teórica}

Nesse tópico, abordam-se teorias que suportam a governança no Estado, as determinações legais sobre a obrigatoriedade de sistemas de custeamento e faz-se uma discussão sobre o princípio constitucional da eficiência e da sua evidencia- 
ção contábil para a prestação de contas (accountability) no setor público para a minimização da assimetria informacional entre o Estado e a sociedade.

\section{Teorias que estruturam a governança no Estado}

Antes de discorrer sobre as teorias que estruturam a governança no Estado é necessário compreendê-la. Para tanto, recorre-se ao conceito do Cadbury Committee (1992), que define a governança dizendo "é o sistema e a estrutura de poder que regem os mecanismos através dos quais as companhias são dirigidas e controladas." Esse conceito reflete a preocupação do Cadbury Committee com a governança corporativa no setor privado. Contudo, ele foi usado como base para o desenvolvimento da primeira estrutura de governança corporativa para o setor público, pelo Instituto Britânico de Finanças e Contabilidade Pública (Cifpa), em 1995. Em 2001, o Comitê do Setor Público da Federação Internacional de Contadores (Ifac) ${ }^{1}$ criou uma contribuição significativa para o desenvolvimento da governança na gestão pública, ao publicar o estudo 13, focado em formas de governança na gestão pública, especialmente no que tange à responsabilidade do grupo governante e da entidade controlada pelo setor público.

Considerando o conceito de governança, pode-se dizer que a governança no Estado está estruturada em contribuições de três teorias: a primeira delas é a Teoria da Firma (Theory of the Firm), desenvolvida pelo matemático e economista Alfred Marshall (1842-1924), em seu livro The principles of economics, propagando a maximização de lucros por parte das empresas como objetivo dessas instituições. E, com base nessa teoria, Ronald Coase (1937), em seu seminal paper, A natureza da firma, caracterizou a firma como uma região de troca sobre a qual o sistema de mercado era suprimido e a alocação de recursos era realizada, ao invés de mercado, por autoridade e direção. Sua preocupação centrava-se nos custos de contratação com o mercado, já que, para ele, as atividades necessárias devem ser incluídas dentro da firma sempre que os custos de mercado forem maiores que os custos de usar a autoridade direta. A segunda é a Teoria dos Contratos na qual Alchian e Demsetz (1972) opõem-se à noção de que as atividades dentro da firma são governadas pela autoridade e, corretamente, enfatizam o papel do contrato como veículo para a troca voluntária. A terceira é a Teoria da Agência, de Jensen e Meckling

\footnotetext{
${ }^{1}$ Public Sector Committee (PSC) — International Federation of Accountants (Ifac).
} 
(1976), que evidencia que a separação entre proprietários e administradores cria uma relação de agência e os problemas da assimetria informacional entre o agente e o principal.

É no contexto dessas três teorias (firma, contratos e agência) que se expande a necessidade de observar as afirmações de Coase (1937) de que, sempre que o custo de mercado for maior que o custo de produção direta, deve-se optar pela produção direta. Assim, entende-se que essa posição deve ser assumida pelo Estado que, nesse caso, não difere em nada de uma firma, ao contrário, assemelha-se a ela, ao suprir com serviços as necessidades da sociedade.

O Estado poderia comprar serviços pelos quais, no entanto, teria que pagar. Ele toma, então, a decisão de produzi-los. Essa produção acontece a custo para o Estado, pois o governo contrata pessoas, compra matéria-prima, constrói prédios públicos para a produção de bens e serviços, enfatizando um conjunto de contratos entre os fatores de produção, que deve ser acompanhado por meio de sistemas de custeamento, para que o Estado possa conhecer seus custos e, assim, tomar decisões de produzir internamente ou de comprar os serviços e produtos de que necessita, conforme ensina Coase (1937).

\section{Sistemas de custeamento}

Para discorrer sobre sistemas de custeamento, é necessário observar que, no Brasil, esse tema é tratado pelo legislador brasileiro há quase cinco décadas. Com a promulgação da Lei no 4.320/1964, foi introduzida a obrigatoriedade, para a administração pública brasileira, em manter instrumentos para a aferição dos custos, como pode ser lido no art. 99 da já referida lei: "os serviços públicos industriais, ainda que não organizados como empresa pública ou autárquica, manterão contabilidade especial para determinação dos custos, ingressos e resultados, sem prejuízo da escrituração patrimonial e financeira comum." O leitor poderia não concordar que o legislador da época quisesse com a redação do artigo tratar de sistema de custos como o fez o legislador de 2000, quando redigiu o $\S 3^{\circ}$ do inciso VI do art. 50, da Lei Complementar no 101: "A administração pública manterá sistema de custos que permita a avaliação e o acompanhamento da gestão orçamentária, financeira e patrimonial." Para se fazer um relacionamento entre as duas vontades, aquela de 1964 e a de 2000, é preciso voltar no tempo, dado que, na década de 1960 , não se conhecia outra nomenclatura para a definição de custeamento de serviços. A literatura da época tratava apenas de custos industriais e, assim, o 
legislador apenas adotou o que a academia tinha consagrado como sistemas de custeamento sob a chancela de custos industriais.

Pode ser observado, no dispositivo legal de 2000, que o legislador não foi assertivo ao redigi-lo, uma vez que utiliza o termo "sistema de custos". Repete, assim, a falta de assertividade de 1964 quando utiliza "contabilidade especial para determinação dos custos" ao invés de sistemas de custeamento, sistemas de custeio ou sistemas de acumulação de custos de produtos ou serviços produzidos pela administração pública.

Se, de um lado, isso pode gerar questionamentos, por outro, deixa o gestor livre para tratar do tema como melhor lhe aprouver. Contudo, quando o responsável técnico for estruturar um sistema de custeamento na administração pública, é importante que deixe claro qual é o sistema de custeamento que está utilizando, no referido cálculo, se por ordem ou processo/contínuo, e evidencie qual é o escopo do referido uso da informação produzida, se para formação de estoques ou se para auxiliar a tomada de decisão. Essa clareza deverá, também, demonstrar qual é o método de custeio (absorção, variável direto, $\mathrm{ABC}$ etc.) que se está utilizando e, ainda, qual é o critério de avaliação dos materiais: média ponderada móvel (MPM), primeiro que entra primeiro que sai (Peps), último que entra primeiro que sai (Ueps), preço específico (PE), custo de reposição (CR) etc. Pois o sistema de custeamento a ser implantado na administração pública deve ser um daqueles já conhecidos e reconhecidos pela academia. Além disso, é necessário que a gestão pública atenda ao princípio constitucional da eficiência para melhor evidenciar a importância da estruturação de sistemas de custeamento na administração pública.

\section{A evidenciação da eficiência no setor público}

A Emenda Constitucional no 19, de 1998, traz para a Constituição brasileira nova redação para o art. 37: "A administração pública direta e indireta de qualquer dos Poderes da União, dos estados, do Distrito Federal e dos municípios obedecerá aos princípios de legalidade, impessoalidade, moralidade, publicidade e eficiência ...”. Ao introduzir o princípio da eficiência a ser obedecido pelos poderes brasileiros, amplia a importância do art. 85 da Lei no 4.320/1964, que trata da organização dos serviços de contabilidade, dizendo:

Os serviços de contabilidade serão organizados de forma a permitir o acompanhamento da execução orçamentária, o conhecimento da composição patrimonial, a determinação dos custos dos serviços industriais, o levantamento 
dos balanços gerais, a análise e a interpretação dos resultados econômicos e financeiros.

Desse modo, antes da introdução do princípio constitucional e para contribuir para o atendimento do referido artigo da Lei no 4.320/1964, no que se refere à análise e à interpretação dos resultados econômicos, Slomski apresenta em sua dissertação de mestrado, defendida em 1996, na Universidade de São Paulo, a demonstração do resultado econômico. Instrumento de evidenciação da eficiência na administração pública que, em 2008, torna-se demonstração a ser publicada de maneira obrigatória pelos entes públicos, de acordo com a Resolução CFC no 1.133/2008 do Conselho Federal de Contabilidade (CFC) em que diz, textualmente: "a demonstração do resultado econômico evidencia o resultado econômico de ações do setor público". Reafirmando a importância da apresentação da demonstração do resultado econômico, a Secretaria do Tesouro Nacional, por meio da Portaria no 749/2009, orienta a elaboração de duas novas demonstrações contábeis: a demonstração dos fluxos de caixa e a demonstração do resultado econômico, esta última, diferentemente do CFC, a STN orienta que seja elaborada de maneira facultativa, com o objetivo de produzir evidenciação de eficiência na administração pública.

O modelo conceitual desenvolvido por Slomski (1996) parte da premissa de que os controles exclusivamente orçamentários deixam de captar o grau de eficiência com que são prestados os serviços públicos. O autor entende que, na prestação de serviços públicos, há uma receita que não está explicitada na contabilidade de entidades públicas, denominada receita econômica, que é encontrada, segundo Slomski (1996:62), "pela multiplicação do custo de oportunidade, que o cidadão desprezou ao utilizar o serviço público, pelos serviços que ela tenha efetivamente executado". O CFC, na resolução já referida, define receita econômica como: "o valor apurado a partir de benefícios gerados à sociedade pela ação pública, obtido por meio da multiplicação da quantidade de serviços prestados, bens ou produtos fornecidos, pelo custo de oportunidade." Como pode ser observado, pouco foi alterado, entre a definição de receita econômica de Slomski (1996) e do CFC (2008): a essência foi mantida.

A Resolução no 1.133/2008 do CFC é assertiva ao dizer que:

A demonstração do resultado econômico deve ser elaborada considerando sua interligação com o sistema de custos, e apresentar, na forma dedutiva, pelo menos a seguinte estrutura: (a) receita econômica dos serviços prestados e dos bens ou dos produtos fornecidos; (b) custos e despesas identificados com a execução da ação pública; e (c) resultado econômico apurado. 
Dessa forma se poderá observar a eficiência na prestação de serviços da entidade.

A Secretaria do Tesouro Nacional (STN), por meio da Portaria no 749/2009, aprova e inclui o Anexo 20 (demonstração do resultado econômico) da Lei no 4.320, de 17 de março de 1964, reforçando a importância da mensuração do resultado econômico no setor público como já havia feito o CFC, conforme está no quadro 1.

\section{Quadro 1 \\ Anexo 20 - Lei no $4.320 / 1964$}

\begin{tabular}{|c|c|c|}
\hline \multicolumn{3}{|c|}{$\begin{array}{c}\text { "Ente da Federação" } \\
\text { Demonstração do Resultado Econômico } \\
\text { Período: --/--/---- a --/--/---- }\end{array}$} \\
\hline Especificação & Exercício atual & Exercício anterior \\
\hline $\begin{array}{l}\text { 1. Receita econômica dos serviços prestados e dos bens ou dos } \\
\text { produtos fornecidos }\end{array}$ & & \\
\hline $\begin{array}{l}\text { 2. (-) Custos diretos identificados com a execução da ação } \\
\text { pública }\end{array}$ & & \\
\hline 3. Margem bruta & & \\
\hline $\begin{array}{l}\text { 4. (-) Custos indiretos identificados com a execução da ação } \\
\text { pública }\end{array}$ & & \\
\hline 5. Resultado econômico apurado & & \\
\hline
\end{tabular}

Slomski (1996), ao se referir ao resultado econômico, afirma que a mensuração do resultado econômico, preconizada naquele estudo, viabiliza a análise e interpretação dos resultados econômicos da entidade pública, conforme estabelece o art. no 85 da Lei no 4.320/1964.

\section{Accountability na administração pública}

A crise do Estado é um fenômeno mundial, cujas causas são numerosas, passando pela ampliação acentuada das funções estatais, o que coincide com a transformação de um estado liberal para um estado garantidor do bem-estar social (welfare state), até o processo intenso de globalização da economia vivido nos últimos anos, que certamente modificou o papel do Estado (Cardoso, 2006).

É nesse contexto que, em vários países, se inicia, nas décadas de 1970 e 1980, um processo de reforma da administração pública, passando-se para o 
que Bresser-Pereira (2006:28-36) chama de "administração pública gerencial". Nesse modelo, a ênfase está no cidadão e nos resultados, exigindo-se do gestor público eficiência, transparência e, sobretudo, qualidade na prestação dos serviços públicos e no exercício das funções estatais.

Ao mesmo tempo que se buscam novos paradigmas para a gestão pública, a corrida pela eficiência e qualidade deve ser acompanhada de novos padrões de accountability no setor público, de modo a oferecer ao cidadão informações que possibilitem a avaliação de desempenho do administrador público. Slomski (2005) defende que o Estado democrático é, na verdade, uma associação obrigatória de seus cidadãos, em que eles elegem seus dirigentes e representantes, sob a disciplina de um contrato (em nosso caso, a Constituição Federal), mediante contribuições pecuniárias, necessárias à prestação dos serviços públicos e investimentos. Sob esse ponto de vista, o autor afirma que a forma mais adequada seria considerar-se o Estado como uma sociedade peculiar, em que os sócios (cidadãos), ao recolherem seus tributos, estariam integralizando o capital para custeio e investimento, necessários à prestação dos serviços públicos aos sócios, o que, por sua vez, representaria a distribuição de renda em contrapartida ao investimento individual (Mello, 2006). Assim, entende-se que a prestação de contas na administração pública deve incluir, sempre que possível, a demonstração do resultado econômico da entidade para que o cidadão/sócio da coisa pública possa compreender quão eficiente é a gestão em determinada gestão.

Sob qualquer prisma que se observe a relação entre o Estado e seus cidadãos, não é possível olvidar-se da necessidade de prestação de contas ampla e transparente por parte dos agentes públicos, possibilitando avaliação sobre o desempenho dos gestores públicos.

\section{Metodologia}

Nesse tópico, apresenta-se a metodologia utilizada para a realização da pesquisa, com o objetivo de subsidiar futuros pesquisadores, para que possam compreender como ela foi desenvolvida e, assim, possam reaplicá-la em outro ente público.

\section{Campo da pesquisa: ente pesquisado}

A pesquisa foi realizada de modo intencional e por acessibilidade na Procuradoria-Geral do Município de São Paulo (PGMSP) que é um órgão da admi- 
nistração municipal e é composta por cinco departamentos: fiscal, desapropriações, patrimonial, judicial e procedimentos disciplinares. Também integra esse órgão a Assessoria Jurídico-consultiva. Tem por função privativa o exercício da representação judicial do município, a inscrição e a cobrança judicial e extrajudicial da dívida ativa, os procedimentos administrativos e judiciais de proteção e controle do patrimônio imobiliário, bem como as atividades de consultoria e assessoramento jurídico, esta última de forma não exclusiva. Os dados referem-se ao exercício financeiro de 2006.

\section{A coleta de dados}

Preliminarmente ao trabalho de coleta de dados, foi realizada reunião com o procurador geral do município, na qual foi exposta a proposta do estudo e solicitada a autorização da direção do órgão para prosseguimento. A partir daí, foram realizadas reuniões com a diretoria de cada departamento da PGMSP, em que foram expostos os objetivos do trabalho e os dados necessários para a sua elaboração, fixando-se um prazo para sua entrega com a coleta de informações relativas aos serviços prestados.

Paralelamente, foram obtidas no setor contábil as informações relativas à execução orçamentária da PGMSP no ano de 2006, discriminadas por unidade orçamentária.

Para a realização da coleta dos dados foram consultados os registros de controle dos serviços prestados em cada um dos departamentos que compõem a PGMSP e, ainda, os relatórios fornecidos pelo Departamento de Contabilidade da PMSP.

\section{Determinação do custo de oportunidade}

Para a apuração do resultado econômico tomou-se o modelo de mensuração do resultado econômico desenvolvido por Slomski (1996), assim, para a mensuração da receita econômica de cada um dos departamentos da PGMSP, foram utilizados alguns critérios para a definição do custo de oportunidade dos serviços prestados, conforme segue:

v os honorários por serviços advocatícios foram encontrados na tabela de honorários publicada pela $\mathrm{OAB} / \mathrm{SP},{ }^{2}$ bem como nas tabelas de valores de

\footnotetext{
${ }^{2}$ Disponível em: <www.oabsp.org.br>.
} 
referência para contratação de serviços de advocacia por instituições financeiras de grande porte, uma do setor público e outra do setor privado. Nesse aspecto, cabe repisar que as atividades inerentes à advocacia pública nem sempre estão discriminadas nas tabelas de honorários, normalmente aplicadas na advocacia privada. Nos casos de ausência de referência, foram considerados os procedimentos que mais se aproximam dos praticados pela PGM;

v os honorários relativos a avaliações e demais serviços de engenharia prestados pela PGM foram obtidos na tabela de honorários do Instituto Brasileiro de Avaliações e Perícias do Estado de São Paulo (Ibape-SP); ${ }^{3}$

- os laudos de avaliação de cálculos judiciais aplicados nas ações de desapropriação foram obtidos na tabela de honorários técnicos do sindicato das empresas de serviços contábeis, assessoramento, perícias, informações e pesquisas do Rio Grande do Sul (Sescon-RS); ${ }^{4}$

- para o cálculo dos serviços de assessoria jurídica e técnica, prestados pelos gabinetes da PGM e dos diversos departamentos, foram considerados os valores de salários médios constantes do cadastro do Datafolha, coletados em 18 de junho de 2007, para os cargos de advogados sênior (assessoria jurídica), engenheiro civil sênior (assessoria técnica) e gerente jurídico (cargos de direção). ${ }^{5}$ Para se adotar critério conservador de valoração desses serviços, considerou-se, ao invés de horas técnicas, o valor de uma cessão mensal de mão de obra (salários conforme acima), acrescidos de 89,15\% a título de encargos sociais e $25 \%$ de BDI, conforme contratação técnica feita pela própria Prefeitura do Município de São Paulo.

Os critérios aplicados a cada um dos casos estão expostos nas notas explicativas (NE) de cada um dos quadros, relacionadas com a apuração da receita econômica de cada departamento da PGMSP. O cálculo do resultado econômico foi realizado utilizando-se o modelo desenvolvido por Slomski (1996), tendo como base a seguinte fórmula: $\operatorname{ReE}=[\mathrm{RE}-(\mathrm{CSP}+\mathrm{D}+\mathrm{CIIS})]$.

Para a quantificação dos serviços produzidos pela PGM, foram considerados apenas aqueles serviços que poderiam, em tese, ser contratados no mercado, cabendo ressaltar que vários procedimentos administrativos e

\footnotetext{
${ }^{3}$ Disponível em: <www.ibape-sp.org.br>.

${ }^{4}$ Disponível em: <www.sescon-rs.com.br $>$.

${ }^{5}$ Disponível em: <www.datafolha.folha.uol.com.br $>$.
} 
operacionais realizados pelos departamentos daquele órgão não foram considerados no cálculo em razão da dificuldade de mensuração do seu custo de oportunidade. Assim, pode-se concluir que, nesse aspecto, o valor da receita econômica foi calculado de forma conservadora, uma vez que tais serviços são indispensáveis à realização da advocacia pública do município de São Paulo. Como exemplo, pode-se citar os milhares de expedientes internos em que a PGMSP presta informações a outros órgãos do município ou, ainda, o enorme volume de atendimentos ao público, também de difícil mensuração do custo de oportunidade.

Da mesma forma, uma enorme quantidade de procedimentos judiciais (andamento de processos) não foi considerada no cálculo da receita econômica. Utilizou-se, no caso dos estoques de processos existentes, a premissa de que uma contratação de serviços advocatícios de grande volume poderia incluir, como atribuição do contratado, o andamento dos processos já em tramitação, ficando a remuneração respectiva incluída nos honorários especificados nas tabelas anexas.

Embora vários procuradores do município estejam lotados nas assessorias técnicas e jurídicas das diversas secretarias municipais, optou-se por não considerar nem as despesas com os seus salários nem tampouco os serviços por ele prestados. A razão dessa exclusão é a dificuldade de determinação das despesas com salários e encargos desses procuradores, pois eles estão onerando os respectivos orçamentos das secretarias em que estão lotados.

\section{Método e procedimentos de análise dos dados}

A análise dos dados tem como objetivo organizá-los de forma a permitir o fornecimento de respostas ao problema da pesquisa. Nesse sentido, analisou-se por meio do cálculo por regra de três com os valores unitários dos salários. Os dados receberam tratamentos disponíveis em planilha de Excel, especialmente preparada para essa finalidade.

Para Gil (2007:125), "após, ou juntamente com a análise, pode ocorrer também a interpretação dos dados, que consiste, fundamentalmente, em estabelecer a ligação entre os resultados obtidos com outros já conhecidos". O processo de análise e de interpretação dos dados envolveu diversos procedimentos, tais como a codificação das respostas, tabulação dos dados e cálculos estatísticos. 


\section{Resultados e discussões}

Nesse tópico serão apresentados os resultados e as discussões sobre os resultados encontrados, e será apurado o resultado econômico da entidade pesquisada em função dos achados.

\section{Mensuração da receita econômica}

Para a mensuração da receita econômica de cada um dos departamentos que compõem a PGMSP foram estabelecidos alguns critérios gerais: foram considerados apenas os procedimentos executados no ano de 2006, excluindo-se do cálculo as petições e manifestações diversas, produzidas em grande volume pelos departamentos em razão do enorme estoque de ações em andamento. Considerou-se, nesse caso, que uma suposta contratação de serviços advocatícios no mercado fosse atraente o suficiente para compensar o estoque de processos já existente; embora normalmente os serviços de advocacia sejam contratados com cláusula de êxito, em razão da impossibilidade de se obter, com precisão, informações relativas ao valor das causas em andamento, optou-se por não considerar esses valores no custo de oportunidade, estabelecendo-se sempre valores fixos para cada procedimento.

\section{Receita econômica do Departamento Fiscal da PGMSP}

A seguir, na tabela 1 , são apresentadas as quantidades de serviços produzidos pelo departamento e o preço de mercado (custo de oportunidade da PMSP) para a contratação do serviço, bem como o cálculo do valor total do ano, por serviço, e a receita econômica gerada pelo departamento para a PGMSP.

$$
\text { Tabela } 1
$$

Receita econômica produzida pelo Departamento Fiscal da PGMSP (exercício de 2006)

\begin{tabular}{|lrcrc|}
\hline Item & Quantidade & Preço de mercado & \multicolumn{1}{c|}{ Total (R\$) } & Obs. \\
\hline Execuções ajuizadas & 221.415 & 350,00 & $77.495 .250,00$ & 1 \\
Petições de restauração de & 183 & $1.082,47$ & $198.092,01$ & 2 \\
autos & & & & \\
Impugnações & 1.639 & $1.082,47$ & $1.774 .168,33$ & 2 \\
\hline
\end{tabular}




\begin{tabular}{|lcccc|}
\hline Item & Quantidade & Preço de mercado & \multicolumn{1}{c}{ Total (R\$) } & Obs. \\
\hline Recursos & 4.228 & $1.082,47$ & $4.576 .683,16$ & 2 \\
Contrarrazões & 3.026 & $1.082,47$ & $3.275 .554,22$ & 2 \\
Respostas em execução de pré- & 6.010 & $1.082,47$ & $6.505 .644,70$ & 2 \\
executividade & & & & \\
Petições e cotas em autos & 107.555 & - & & 3 \\
judiciais & & & $1.082,47$ & 2 \\
Ações ajuizadas & 1 & $1.082,47$ & $1.576 .076,32$ & 2 \\
Defesas da PMSP & 1.456 & $1.082,47$ & $497.936,20$ & 2 \\
Execução pelo art. 730 & 460 & $1.082,47$ & $86.597,60$ & 2 \\
Embargos art. 730 (Fisc. 33) & 80 & $1.082,47$ & $104.286 .148,72$ & 4 \\
Quitações e parcelamentos & 142.376 & 732,47 & & \\
administrativos & & & $777.213,46$ & 2 \\
Prazos judiciais de fisc. 33 & 718 & $1.082,47$ & & \\
(falência) - impugnações & & & & \\
aos embargos, recursos e & & & & \\
contrarrazões & & & &
\end{tabular}

Obs.:

(1) As ações aqui consideradas são, em sua imensa maioria, execuções fiscais relativas a débitos envolvendo tributos municipais. O trâmite dessas ações, após o seu ajuizamento, enseja uma série de manifestações do procurador visando à penhora de bens do devedor, requisito para o seu prosseguimento. Assim, considerou-se como referência o valor pago por instituição financeira a título de remuneração pelo ajuizamento da cobrança judicial de seus créditos, em contratos com grande volume de processos.

(2) Foi considerado o valor mínimo para procedimentos judiciais similares estabelecidos na tabela de honorários da OAB.

(3) Adotou-se como critério que uma contratação de serviços no mercado poderia incluir tais procedimentos sem previsão de cobrança, uma vez que os honorários devidos pelos demais os compensariam.

(4) Para tornar atrativa a cobrança amigável, que envolve uma grande estrutura de atendimento, adotou-se o critério de se pagar a diferença entre o valor padrão para procedimentos judiciais da $\operatorname{OAB}(\mathrm{R} \$ 1.082,47)$ e o valor pago pelo ajuizamento de ações $(R \$ 350,00)$ que somaria $(R \$ 732,47)$.

\section{Receita econômica do Departamento Judicial da PGMSP}

Na tabela 2 são apresentadas as quantidades de serviços produzidos pelo departamento e o preço de mercado (custo de oportunidade da PMSP) para contratação do serviço, bem como o cálculo do valor total do ano, por serviço, e a receita econômica gerada pelo departamento para a PGMSP. 
Tabela 2

\section{Receita econômica produzida pelo Departamento Judicial da PGMSP (exercício de 2006)}

\begin{tabular}{|lcccc|}
\hline Item & Quantidade & Valor de mercado & \multicolumn{1}{c|}{ Total (R\$) } & Obs. \\
\hline Contestações/ações & 6.431 & $1.082,47$ & $6.961 .364,57$ & 2 \\
Execuções ajuizadas & 52.116 & 350,00 & $18.240 .600,00$ & 1 \\
Audiências & 2.982 & 432,99 & $1.291 .176,18$ & 3 \\
Processos administrativos & 76.015 & 157,64 & $11.983 .004,60$ & 4 \\
Expedientes administrativos & 8.511 & 157,64 & $1.341 .674,04$ & 5 \\
Convocações & 4.403 & - & - & 7 \\
Atendimentos & 14.279 & - & - & 7 \\
Acordos & 5.315 & 732,47 & $3.893 .078,05$ & 6 \\
Carnês & 16.176 & 732,47 & $11.848 .434,72$ & 6 \\
Embargos e execuções & 3.240 & $1.082,47$ & $3.507 .202,80$ & 1 \\
Recursos em geral & 12.540 & $1.082,47$ & $13.574 .173,80$ & 1 \\
Petições diversas (fora as emitidas) & 34.692 & - & - & 7 \\
Total & & & $72.640 .708,76$ & \\
\hline
\end{tabular}

Obs.:

(1) As ações aqui consideradas são, em sua imensa maioria, execuções fiscais relativas a débitos relativos a multas por infrações às posturas municipais. O trâmite dessas ações, após o seu ajuizamento, enseja uma série de manifestações do procurador, visando à penhora de bens do devedor, requisito para o seu prosseguimento. Assim, considerou-se como referência o valor pago por instituição financeira a título de remuneração pelo ajuizamento da cobrança judicial de seus créditos.

(2) Foi considerado o valor mínimo para procedimentos judiciais similares estabelecidos na tabela de honorários da OAB.

(3) Utilizado o valor mínimo de referência da $O A B$ para audiências.

(4) Utilizado o valor mínimo de referência da tabela da OAB para uma hora técnica.

(5) Adotou-se como critério que uma contratação de serviços no mercado poderia incluir tais procedimentos sem previsão de cobrança, uma vez que os honorários devidos pelos demais os compensariam.

(6) Para tornar atrativa a cobrança amigável, que envolve uma grande estrutura de atendimento, adotou-se o critério de se pagar a diferença entre o valor padrão para procedimentos judiciais da $\operatorname{OAB}(\mathrm{R} \$ 1.082,47)$ e o valor pago pelo ajuizamento de ações $(R \$ 350,00)$.

(7) Conforme item "a" das observações gerais.

\section{Receita econômica do Departamento de Desapropriações da PGMSP}

Na tabela 3, são apresentadas as quantidades de serviços produzidos pelo departamento e o preço de mercado (custo de oportunidade da PMSP) para a 
contratação do serviço, bem como o cálculo do valor total do ano, por serviço, e a receita econômica gerada pelo departamento para a PGMSP.

Tabela 3

Receita econômica produzida pelo Departamento de Desapropriações da PGMSP (exercício de 2006)

\begin{tabular}{|lccrc|}
\hline Item & Quantidade & Valor de mercado & \multicolumn{1}{c|}{ Total (R\$) } & Obs. \\
\hline Mandados de segurança & 117 & $2.164,95$ & $253.299,15$ & 1 \\
Ações ajuizadas & 141 & $1.082,47$ & $152.628,27$ & 2 \\
Contestações & 17 & $1.082,47$ & $18.401,99$ & 2 \\
Informações para o prefeito & 761 & $1.082,47$ & $823.759,67$ & 2 \\
Manifestações sobre cálculo judicial & 2.297 & $1.069,00$ & $2.455 .493,00$ & 6 \\
Contrarrazões & 420 & $1.082,47$ & $454.637,40$ & 2 \\
Recursos em geral/Respostas & 1.178 & $1.082,47$ & $1.275 .149,66$ & 2 \\
Petições diversas & 12.670 & 315,28 & $3.994 .597,60$ & 3 \\
Avaliações & 141 & $4.069,00$ & $573.729,00$ & 4 \\
Estimativas & 22 & $1.620,00$ & $35.640,00$ & 5 \\
Total & & & $10.037 .335,74$ & \\
\hline
\end{tabular}

Obs.:

(1) Foi considerado o valor mínimo de honorários para mandados de segurança estabelecido na tabela de honorários da $\mathrm{OAB}$.

(2) Foi considerado o valor mínimo de honorários para procedimentos similares estabelecido na tabela de honorários da $\mathrm{OAB}$.

(3) Embora nos demais departamentos as petições tenham sido excluídas do cálculo da receita econômica, o certo é que pelas peculiaridades do trabalho desenvolvido em Desap esses procedimentos representam trabalho técnico relevante por parte dos procuradores. Nesse caso, utilizou-se o valor mínimo estabelecido pela OAB para o exame de processos judiciais.

(4) Foi considerado o valor de uma avaliação de um imóvel de R\$500 mil pela tabela de honorários do Ibape/SP.

(5) Adotou-se como critério o valor mínimo de honorários para uma avaliação, estabelecido pelo Ibape/SP.

(6) Foram consideradas 4 horas técnicas pelo valor mínimo de honorários estabelecido pelo Sescon-RS.

(7) Conforme item $a$ das observações gerais.

\section{Receita econômica do Departamento Patrimonial da PGMSP}

Na tabela 4, são apresentadas as quantidades de serviços produzidos pelo departamento e o preço de mercado (custo de oportunidade da PMSP) para a contratação do serviço, bem como o cálculo do valor total do ano, por serviço e a receita econômica gerada pelo departamento para a PGMSP. 
Tabela 4

\section{Receita econômica produzida pelo Departamento Patrimonial da PGMSP (exercício de 2006)}

\begin{tabular}{|lrrrr|}
\hline Item & Quantidade & Valor de mercado & \multicolumn{1}{c}{ Total (R\$) } & Obs. \\
\hline Contestações & 298 & $1.082,47$ & $322.576,06$ & 1 \\
Ações ajuizadas & 156 & $1.082,47$ & $168.865,32$ & 2 \\
Informações em mandato de & 137 & $1.082,47$ & $148.298,39$ & 1 \\
segurança & & & & \\
Quotas opinativas & 2.006 & 157,64 & $316.225,84$ & 3 \\
Pareceres & 632 & $1.082,47$ & $684.121,04$ & 1 \\
Análise de certidões imobiliárias e & 673 & 865,98 & $582.804,54$ & 1 \\
averbações registrárias & & & & \\
Audiências & 22 & 432,99 & $9.525,78$ & 1 \\
Sustentações orais & 1 & $2.164,95$ & $2.164,95$ & 1 \\
Outras manifestações em juízo & 2.775 & 315,28 & $874.902,00$ & 4 \\
Embargos e execuções de pré- & 3.240 & $1.082,47$ & $3.507 .202,80$ & 1 \\
executividade & & & & \\
Recursos em geral & 1.178 & $1.082,47$ & $1.275 .149,66$ & 1 \\
Reintegraç̃̃es de posse & 12 & $2.164,95$ & $25.979,40$ & 1 \\
Análise de processos & 553 & 315,28 & $174.349,84$ & 4 \\
Avaliações para fins judiciais & 79 & $4.069,00$ & $321.451,00$ & 5 \\
Avaliação para locação & 62 & $2.500,00$ & $155.000,00$ & 6 \\
Estudos de plantas e plantas & 436 & 310,00 & $135.160,00$ & 7 \\
registradas & & & & \\
Vistorias & 4.248 & 620,00 & $2.633 .760,00$ & 8 \\
Estudos de domínio & 1.020 & 865,98 & $883.299,60$ & 1 \\
Plantas elaboradas e croquis & 381 & $1.620,00$ & $617.220,00$ & 9 \\
Total & & & $12.838 .056,22$ & \\
\hline
\end{tabular}

Obs.:

(1) Foi considerado o valor mínimo para procedimentos judiciais similares estabelecidos na tabela de honorários da OAB.

(2) Foi considerado como referência 50\% do valor mínimo para a proposição de uma ação judicial, previsto na tabela de honorários da $\mathrm{OAB}$, considerando-se que os recursos eventualmente interpostos seriam valorados separadamente.

(3) Utilizado o valor mínimo referência da tabela da OAB para uma hora técnica.

(4) Utilizado o valor mínimo referência da tabela da OAB para "exame de processos".

(5) Adotou-se como critério o valor referência do Ibape/SP para uma avaliação de imóvel no valor de R\$ 500 mil, uma vez que em regra os imóveis avaliados pelo departamento são de grande valor.

(6) Adotou-se, conservadoramente, como critério, o valor referência do Ibape/SP para uma avaliação de imóvel cujo valor locatício seja de $R \$ 2,5$ mil por mês.

(7) Adotou-se como critério o valor referência do Ibape/SP para duas horas técnicas (valor unitário R\$155).

(8) Adotou-se como critério o valor referência do Ibape/SP para quatro horas técnicas (valor unitário $R \$ 155$ ).

(9) Adotou-se como critério o valor mínimo de referência do Ibape/SP para laudos técnicos. 


\section{Receita econômica do Departamento de Procedimentos da PGMSP}

Na tabela 5 são apresentadas as quantidades de serviços produzidos pelo departamento e o preço de mercado (custo de oportunidade da PMSP) para a contratação do serviço, bem como o cálculo do valor total do ano, por serviço, e a receita econômica gerada pelo departamento para a PGMSP.

Tabela 5

Receita econômica produzida pelo Departamento de Procedimentos da PGMSP (exercício de 2006)

\begin{tabular}{|lcccc|}
\hline Item & Quantidade & Valor de mercado & \multicolumn{1}{c|}{ Total (R\$) } & Obs. \\
\hline Audiências & 4.555 & 432,99 & $1.972 .269,45$ & 1 \\
Processos relatados & 1.099 & $2.164,95$ & $2.379 .280,05$ & 2 \\
Processos instaurados & 767 & 350,00 & $268.450,00$ & 2 \\
Finais & 269 & $2.164,95$ & $582.371,55$ & 3 \\
Total & & & $5.202 .371,05$ & \\
\hline
\end{tabular}

Obs.:

(1) Foi considerado o valor mínimo para procedimentos judiciais similares estabelecidos na tabela de honorários da OAB.

(2) Foi considerada como referência a diferença entre o valor mínimo para processos administrativos e o valor inicial pago para o ajuizamento de ações por instituição financeira de grande porte. O valor total por processo relatado, no montante de $\mathrm{R} \$ 2.164,95$, foi adotado, tendo em vista que os procedimentos levados a cabo pelo Departamento de Procedimentos exigem grande estrutura operacional com cartórios, atendimento, além da efetivação de intimações, publicações etc. Ademais, os julgamentos exigem mais dois membros, além do procurador, por comissão.

(3) Nesse caso, aplicou-se o valor total, referência da tabela de honorários da OAB para processos administrativos.

\section{Receita econômica da Assessoria Técnica e Jurídica da PGMSP}

Na tabela 6 são apresentados as quantidades de serviços produzidos pelo departamento e o preço de mercado (custo de oportunidade da PMSP) para a contratação do serviço, bem como o cálculo do valor total do ano, por serviço, e a receita econômica gerada pelo departamento para a PGMSP. 
Tabela 6

Receita econômica produzida pela Assessoria Técnica e Jurídica da PGMSP (exercício de 2006)

\begin{tabular}{|lcrrr|}
\hline Item & Quantidade & Valor de mercado & \multicolumn{1}{c|}{ Total (R\$) } & Obs. \\
\hline PGM & & & & \\
Assessoria jurídico-consultiva & 16 & $14.638,05$ & $234.208,80$ & 1 \\
Direção & 1 & $24.574,73$ & $24.574,73$ & 2 \\
Fiscalização & & & & \\
Assessoria jurídica & 3 & $14.638,05$ & $43.914,15$ & 1 \\
Direção & 6 & $24.574,73$ & $147.448,38$ & 2 \\
Judicial & & & & \\
Assessoria jurídica & 3 & $14.638,05$ & $43.914,15$ & 1 \\
Direção & 5 & $24.574,73$ & $122.873,65$ & 2 \\
Desapropriação & & & & \\
Assessoria jurídica & 3 & $14.638,05$ & $43.914,15$ & 1 \\
Assessoria técnica & 2 & $9.383,00$ & $18.766,00$ & 3 \\
Direção & 5 & $24.574,73$ & $122.873,65$ & 2 \\
Patrimonial & & & & \\
Assessoria jurídica & 3 & $14.638,05$ & $43.914,15$ & 1 \\
Direção & 5 & $24.574,73$ & $122.873,65$ & 2 \\
Procedimentos & & & & \\
Assessoria jurídica & 9 & $14.638,05$ & $131.742,45$ & 1 \\
Direção & 1 & $24.574,73$ & $24.574,73$ & 2 \\
Total & & & $1.125 .592,64$ & \\
\hline
\end{tabular}

Obs.:

(1) Foi considerado o valor do salário médio para um advogado sênior, publicado no caderno "Empregos" da Folha de S.Paulo, de 8 jul. 2007, acrescido de 89\% de encargos e BDI de 25\% (conforme contratações técnicas da PMSP).

(2) Foi considerado o valor do salário médio para um gerente jurídico, apurado pelo Datafolha (disponível em: $<w w w$. datafolha.com.br>, 18 jun. 2007), acrescido de 89\% de encargos e BDI de 25\% (conforme contratações técnicas da PMSP).

(3) Foi considerado o valor do salário médio para um engenheiro civil sênior, apurado pelo Datafolha (disponível em: <www.datafolha.com.br>, 18 jun. 2007), acrescido de 89\% de encargos e BDI de 25\% (conforme contratações técnicas da PMSP).

\section{Evidenciação dos custos e das despesas incorridas}

Na tabela 7 são apresentadas as despesas relacionadas aos serviços da PGMSP, bem como a depreciação incorrida no período. Para a atribuição de custos diretos e indiretos serão considerados os percentuais de $80 \%$ e $20 \%$ sobre os 
gastos totais, respectivamente, uma vez que não existem dados para a sua separação.

Tabela 7

\section{Demonstrativo dos custos e despesas da PGMSP}

\begin{tabular}{|lrc|}
\hline Especificação & \multicolumn{1}{c|}{ Valor (R\$) } & Obs. \\
\hline Pessoal & $83.763 .000,00$ & 1 \\
Encargos sociais (Iprem/Pasep) & $19.265 .000,00$ & 2 \\
Auxílio alimentação & $2.366 .000,00$ & 1 \\
Auxílio transporte & $733.000,00$ & 1 \\
Material de consumo & $516.000,00$ & 3 \\
Serviços de terceiros & $5.132 .000,00$ & 4 \\
Despesas diversas & $39.000,00$ & 5 \\
Depreciação & $781.000,00$ & 6 \\
Locação de imóveis & $4.887 .180,00$ & 7 \\
Locação de veículos & $576.000,00$ & 8 \\
Total das despesas & $118.058 .180,00$ & \\
\hline
\end{tabular}

Obs.:

(1) Considerou-se a despesa total de SNJ, distribuindo proporcionalmente ao número de servidores na PGM em relação ao total (SNJ-G - 135; PGM - 1.144; Total - 1.279).

(2) Considerou-se o encargo patronal ao Iprem (22\%) e a contribuição ao Pasep (1\%).

(3) Despesa com material de consumo da PGM somado com material de consumo de informática de SNJ (impossível separar o que seria da PGM).

(4) Inclui: passagens e despesas com locomoção; outros serviços de terceiros - pessoa física; outros serviços de terceiros - pessoa jurídica; locação de mão de obra. Neste item foram incluídos $R \$ 3,4$ milhões relativos a contrato de processamento de dados com a Prodam, que em 2006 estavam incluídos em contrato geral da Prefeitura e em 2007 foi desmembrado.

(5) Inclui: diárias-civil; obrigações tributárias e contributivas.

(6) Para veículos, móveis e equipamentos considerou-se equivalente ao investimento realizado no exercício em equipamentos e material permanente $=281$. Para imóveis, considerou-se que eles já se encontram integralmente depreciados, considerando apenas a depreciação de $5 \%$ a.a. de reforma ampla efetuada em edifício, concluída em 2004, com valor total de cerca de $\mathrm{R} \$ 10$ milhões.

(7) Tendo em vista que os prédios ocupados pela PGM já estão integralmente depreciados, considerou-se, para efeito de despesa, o valor locatício de prédios similares na mesma região, considerando-se a área total de $22.435 \mathrm{~m}^{2}$, ocupada pela PGM nos quatro edifícios.

(8) O valor utilizado como referência ( $R \$ 19 / \mathrm{m}^{2}$ ) estão em consonância com valores atualmente pagos a título de aluguel pela municipalidade em contratos recentemente firmados para imóveis na mesma região. 


\section{Apuração do resultado econômico}

Na tabela 8, apresentada na forma do Anexo 20 da Lei no 4.320/1964, utilizou-se o método de custeio por absorção, tendo sido considerado, para o cálculo da receita econômica, o somatório dos serviços realizados por cada um dos departamentos da Procuradoria-Geral do município naquele ano. E as despesas incorridas no ano foram apuradas conforme detalhamento da tabela 7.

Tabela 8

DRE da PGMSP - Anexo 20 da Lei no 4.320/1964

\begin{tabular}{|c|c|c|}
\hline $\begin{array}{c}\text { MUNICÍPIO DE SÃO PAULO } \\
\text { PROCURADORIA-GERAL DO MUNICÍPIO DE } \\
\text { SÃO PAULO } \\
\text { Demonstração do resultado econômico } \\
\text { Período: } 1 / 1 / 2006 \text { a } 31 / 12 / 2006\end{array}$ & Exercício atual & $\begin{array}{l}\text { Exercício anterior } \\
\qquad(*)\end{array}$ \\
\hline $\begin{array}{l}\text { 1. Receita econômica dos serviços prestados } \\
\text { e dos bens ou produtos fornecidos }\end{array}$ & $302.894 .295,11$ & 0,00 \\
\hline Departamento Fiscal & 201.050.447,19 & 0,00 \\
\hline Departamento Judicial & $72.640 .708,76$ & 0,00 \\
\hline Departamento Desapropriações & $10.037 .335,74$ & 0,00 \\
\hline Departamento Patrimonial & $12.837 .839,73$ & 0,00 \\
\hline Departamento Procedimentos Disciplinares & $5.202 .371,05$ & 0,00 \\
\hline Departamento Assessoria Jurídico-consultiva & $1.125 .592,64$ & 0,00 \\
\hline $\begin{array}{l}\text { 2. (-) Custos diretos identificados com a } \\
\text { execução da ação pública }\end{array}$ & $(89.420 .000,00)$ & 0,00 \\
\hline Pessoal & $(67.010 .400,00)$ & 0,00 \\
\hline Encargos sociais (Iprem/Pasep) & $(15.412 .000,00)$ & 0,00 \\
\hline Auxílio alimentação & $(1.892 .800,00)$ & 0,00 \\
\hline Auxílio transporte & $(586.400,00)$ & 0,00 \\
\hline Material consumo & $(412.800,00)$ & 0,00 \\
\hline Serviços de terceiros & $(4.105 .600,00)$ & 0,00 \\
\hline 3. Margem bruta & $213.474 .295,11$ & 0,00 \\
\hline $\begin{array}{l}\text { 4. (-) Custos indiretos identificados com a } \\
\text { ação pública }\end{array}$ & $(28.638 .180,00)$ & 0,00 \\
\hline Pessoal & $(16.752 .600,00)$ & 0,00 \\
\hline Encargos sociais (Iprem/Pasep) & $(3.853 .000,00)$ & 0,00 \\
\hline Auxílio alimentação & $(473.200,00)$ & 0,00 \\
\hline
\end{tabular}

Continua 


\begin{tabular}{|c|c|c|}
\hline $\begin{array}{c}\text { MUNICÍPIO DE SÃO PAULO } \\
\text { PROCURADORIA-GERAL DO MUNICÍPIO DE } \\
\text { SÃO PAULO } \\
\text { Demonstração do resultado econômico } \\
\text { Período: } 1 / 1 / 2006 \text { a 31/12/2006 }\end{array}$ & Exercício atual & $\begin{array}{c}\text { Exercício anterior } \\
\left({ }^{*}\right)\end{array}$ \\
\hline Auxílio transporte & $(146.600,00)$ & 0,00 \\
\hline Material consumo & $(103.200,00)$ & 0,00 \\
\hline Serviços de terceiros & $(1.026 .400,00)$ & 0,00 \\
\hline Despesas diversas & $(39.000,00)$ & 0,00 \\
\hline Depreciação & $(781.000,00)$ & 0,00 \\
\hline Locação de imóveis & $(4.887 .180,00)$ & 0,00 \\
\hline Locação de veículos & $(576.000,00)$ & 0,00 \\
\hline 5. Resultado econômico apurado & $184.836 .115,11$ & 0,00 \\
\hline
\end{tabular}

(*) Não foi apurado o RE do exercício anterior.

O resultado econômico apurado no valor de $\mathrm{R} \$ 184.836 .115,11$ mostra um lucro econômico produzido pela PGMSP, evidenciando que sua operação agrega valor ao município de São Paulo.

\section{Conclusões}

Considerando os resultados pesquisados conclui-se que o objetivo deste artigo - discorrer sobre a demonstração do resultado econômico e sistemas de custeamento como instrumentos de evidenciação do cumprimento do princípio constitucional da eficiência, produção de governança e accountability no setor público - foi atingido.

Os resultados da pesquisa empírica sugerem que o resultado econômico possibilita a evidenciação do cumprimento do princípio constitucional da eficiência ao comparar a receita econômica produzida ( $\mathrm{R} \$ 302.894 .295,11)$ - custo de oportunidade do município - aos custos e despesas incorridos na sua prestação ( $\mathrm{R} \$ 118.058 .180,00)$, apontando um resultado econômico ( R\$ 184.836.115,11) - lucro econômico — , e criam novo paradigma relacionado aos aspectos de governança e accountability na gestão pública, capaz de produzir informação à sociedade e ao administrador público para a tomada de decisões gerenciais.

Com base no resultado econômico, pode-se fazer uma reflexão acerca do que está contido no conceito de governança. Para o Cadbury Committee 
(1992) "é o sistema e a estrutura de poder que regem os mecanismos através dos quais as companhias são dirigidas e controladas." Dirige-se e controla-se o Estado pelo gasto com determinado serviço, arrecada-se tributos que são consumidos sem a preocupação da evidenciação de sua eficiência ou de sua eficácia. O Comitê do Setor Público do Ifac criou uma contribuição significativa para o desenvolvimento da governança na gestão pública, no que tange à responsabilidade do grupo governante e da entidade controlada pelo setor público. Contudo, essa prestação de contas foca-se na comparação entre o que foi arrecadado e o que foi gasto, sem a preocupação com o cumprimento e evidenciação do princípio constitucional brasileiro da eficiência.

O resultado da mensuração do resultado econômico da PGMSP, referente ao exercício financeiro de 2006, apontou uma receita econômica de $\mathrm{R} \$ 302.894 .295,11$ e um custo dos serviços prestados no montante de $\mathrm{R} \$$ 118.058.180,00. Como ensina Ronald Coase (1937), em seu artigo "A natureza da firma", "a firma pode ser caracterizada como uma região de troca na qual o sistema de mercado era suprimido e a alocação de recursos era realizada, ao invés de mercado, por autoridade e direção". Entende-se, corroborando os dizeres de Coase, que o Estado, quando institui órgãos para a prestação de serviços, também pode ser caracterizado como uma região de troca na qual o sistema de mercado é suprimido e a alocação de recurso é realizada por autoridade e direção. Na PGMSP ficou evidenciada uma alocação de recursos de $\mathrm{R} \$ 118.058 .180,00$, distribuídos entre custos diretos $\mathrm{R} \$ 89.420 .000,00$ e custos indiretos $\mathrm{R} \$ 28.638 .180,00$, capturados pelo sistema de custeamento por processo e pelo método de custeio por absorção. A preocupação de Coase centrava-se nos custos de contratação com o mercado, pois, para ele, "as atividades necessárias devem ser incluídas dentro da firma sempre que os custos de mercado forem maiores que os custos de usar a autoridade direta", nesse sentido, observa-se o acerto da Prefeitura Municipal de São Paulo (PMSP) em manter a PGMSP, já que o custo de oportunidade da PMSP para a contratação com o mercado era de $\mathrm{R} \$ 302.894 .295,11$.

A PMSP contrata servidores e aloca $R \$ 118.058 .180,00$. Coase enfatiza que o mercado é suprimido e o serviço é produzido por autoridade e direção interna; Alchian e Demsetz (1972), valendo-se dos princípios da teoria dos contratos, opõem-se a Coase no sentido de que as atividades dentro da firma são governadas pela autoridade e, "corretamente, enfatizam o papel do contrato como veículo para a troca voluntária". Ao contratar servidores, a PMSP assina um contrato com cada um dos servidores no qual ela paga um salário mensal e o servidor lhe presta um serviço, independentemente de seu valor no mercado, que no caso estudado superou a alocação de recursos em 157\%, 
evidenciando que houve eficiência na produção dos serviços relacionados ao contrato firmado.

Por outro lado, apesar do resultado econômico ter evidenciado um lucro econômico de $\mathrm{R} \$ 184.836 .115,11$ existe uma assimetria informacional entre Estado e sociedade ao não ser evidenciado este valor. A prestação de contas, antes da Portaria no 749/09 da STN, apenas evidenciava o consumo de recursos sem evidenciar a eficiência do gasto público, contribuindo significativamente para a geração de problemas de assimetria informacional entre o agente e o principal. A PMSP poderia comprar serviços, pelos quais, no entanto, teria que pagar o preço de R $\$ 302.894 .295,11$, no entanto, ela toma a decisão de produzi-los com uma alocação de recursos no montante de R $\$ 118.058 .180,00$ e, ao produzir internamente, gera um lucro econômico de $\mathrm{R} \$ 184.836 .115,11$. Muito se fala sobre a ineficiência e ineficácia da administração pública e sobre a vocação do setor privado para a prestação de alguns serviços públicos, supostamente com mais qualidade e eficiência.

Não está no escopo deste artigo discutir quais serviços devem ou não ser prestados pelo poder público. Entretanto, para que essa discussão não se produza sob premissas equivocadas, é indispensável que haja aprofundamento nas investigações sobre a eficácia ou a ineficácia do setor público. Não se pode discutir a conveniência da presença do Estado em determinada atividade, sob o argumento da ineficiência e/ou da ineficácia, sem que se tenha um diagnóstico profundo desses tópicos.

No caso da PGMSP, muito além de se questionar o caráter público de suas atividades, que como atividade típica de Estado deve permanecer subordinada ao poder público, a apuração do resultado econômico revela o quanto essa sistemática poderá enriquecer e aprimorar a gestão do órgão.

\section{Referências}

ALCHIAN, Armen A.; DEMSETZ, Harold. Production, information costs, end economic organization. The American Economic Review, v. 62, n. 5, p. 777-795, 1972.

BRASIL. Lei no 4.320, de 17 de março de 1964.

. Carta Constitucional, 1988.

. Lei de Responsabilidade Fiscal, de 4 de maio de 2000.

BRESSER-PEREIRA, Luiz Carlos. Reforma do Estado para a cidadania. 34. ed. Brasília: Enap, 1998. 
CADBURY COMMITTEE. Report of the committee on the financial aspects of corporate governance. London, 1992. Disponível em: < www.ags.gov.au>. Acesso em: 5 ago. 2005.

CARDOSO, Fernando Henrique. Reforma do Estado. In: BRESSER-PEREIRA, Luiz Carlos; SPINK, Peter (Orgs.). Reforma do Estado e administração pública gerencial. 7. ed. Rio de Janeiro: FGV, 2006.

CIFPA (Chartered Institute of Public Finance and Accountancy). Corporate governance: a framework for public service bodies. London, 1995. Disponível em: <www. cipfa.org.uk>. Acesso em: 5 ago. 2005.

COASE, Ronald. The nature of the firm. Economica, v. 4, n. 16, p. 386-405, 1937. CONSELHO FEDERAL DE CONTABILIDADE. Resolução nำ 1.133, de 23 de novembro de 2008.

GIL, A. C. Como elaborar projetos de pesquisa. São Paulo: Atlas, 2007.

IFAC (International Federation of Accountants). Governance in the public sector: a governing body perspective. New York, 2001.

JENSEN, Michael C.; MECKLING, Willian H. Theory of the firm: managerial behavior, agency costs and ownership structure. Journal of Financial Economics, v. 3, p. 305-360, 1976.

MARSAHL, Alfred. Principles of economics. New York, Amherst, 1997.

MELLO, Gilmar Ribeiro de. Governança corporativa no governo federal brasileiro. 2006. 119 f. Dissertação (Mestrado em Ciências Contábeis ) — FEA/USP, São Paulo.

SECRETARIA DO TESOURO NACIONAL. Portaria nํㅜ 749, de 15 de dezembro de 2009.

SLOMSKI, Valmor. Mensuração do resultado econômico em entidades públicas: uma proposta. 1996. 82 f. Dissertação (Mestrado em Controladoria e Contabilidade) — FEA/USP, São Paulo.

. Controladoria e governança na gestão pública. São Paulo: Atlas, 2005. 